\title{
Forum
}

\section{Collision Avoidance for Oarsmen on the Tideway}

\author{
R. G. Prince \\ (Barrister, London Rowing Club)
}

I. GENERA L. There are two places where landsmen and seamen are likely to come into conflict: (i) in the pubs around Portsmouth Docks; and (ii) in tidal estuaries such as the Thames. There is, however, an intermediate class of person, represented nowadays almost entirely by more or less amateur oarsmen and women, which is that of watermen. I am proud to consider myself a member of all three.

While the relationship between landlord and patron is squarely governed by what may for this purpose be described as Land Law, the watermen have for centuries followed what has developed as a code whereby boats navigating against the tide give way to those navigating with it. However, 'upon the high seas and in all waters connected therewith navigable by seagoing vessels' (Rule I (a)), collision avoidance is governed by the International Regulations for Preventing Collisions at Sea (the colregs), as applied and modified in the case of the Thames Estuary by the Port of London Authority Byelaws (the Byelaws).

To understand the relationship between what might be described as the common law code and the Byelaws, a little knowledge of Constitutional Law is required. It is often forgotten even by Governments (particularly those of a radical persuasion!) that even Parliament cannot make laws, only change them. Thus statutes, (which term here includes the Byelaws) are a battleground between the 'Government' in trying to draft them as broadly as possible, and the Judiciary who at least in theory (since they are effectively appointed by the Government!) interpret them contra proferentem, and thus apply them only to the extent made strictly necessary by their wording. It is in fighting battles such as these that lawyers earn their daily bread.

Thus the colregs apply, even to coastal waters, only insofar as they are navigable by seagoing vessels. It was never intended that they would apply right up to the shore, and that they would there apply to air beds and pedalos! A fortiori they apply only to such part of rivers as is navigable by seagoing vessels.

The concept of a 'narrow channel or fairway' governed by Rule 9 is derived from an open sea which, however, is shallow enough to cause vessels of deep enough draught to follow certain channels. This necessarily follows from Rule 9 (d), which states that 'a vessel shall not cross a narrow channel or fairway if such crossing impedes the passage of a vessel which can safely navigate only within such channel or fairway'.

Ex hypothesi other vessels would not be constrained to follow those channels, else there would be no need for the rule at all; that is, it would be impossible to require 'a vessel of 20 metres in length or a sailing vessel not to impede the passage of a vessel which can safely navigate only in a narrow channel or fairway' (Rule $9(\mathrm{~b})$ ) if there is nowhere else for her to go!

Thus it appears that a river is not per se a 'narrow channel or fairway', but only that 
part of the river which is navigable by seagoing vessels. The significance of this is obvious: outside the narrow channel or fairway the colregs, in particular Rule 9 thereof, do not apply; thus vessels outside the narrow channel are not required to "keep as near to the outer limit of the channel or fairway which lies on her starboard side as is safe and practicable' (Rule 9(a)) (my emphasis throughout).

The converse is also true: any vessel which finds herself at any particular moment in water which could conceivably be navigated by a seagoing vessel (even if the latter can navigate only within a narrow channel or fairway) is, by definition, within the colregs: this begs the whole question of what is meant by a 'sea-going vessel', but that is entirely outside the scope of this article.

The common-law rule presumably arose because, in the Middle Ages, heavily-laden barges were often in effect just drifted up-and-down the river with the tide, and smaller boats got in their way at their peril. While power-driven vessels can simply increase their power, rowing boats (especially if crewed by novices, who are nonetheless perfectly entitled to be on the river) may not be able to make any progress against the tide, and in any event it is certainly not 'practicable' for them to go round the outside of long bends and, in the case where there are shoals, islands, moored boats, and deepwater jetties (such as around Hammersmith, Barnes, and Kew), it is completely unsafe. Similarly, even going with the tide, in rough water it is often necessary for a boat to stay close to the port bank.

However, even then it should be noted that the requirement for other vessels is only to 'give way'. The boat going with the tide is not entitled to blunder on regardless and expect other vessels to scatter like chaff in the wind (as has happened recently to me). If not already easied, the best thing for such other vessels to do is to easy in accordance with Rule 8 (e) ('Action to avoid collision'), and wait for the boat to pass on the outside.

The same may be true of the inside of bends, such as at Fulham, where a boat travelling upriver against the tide at low water is going to be forced by shoals right out into the middle of the river : it may well be much safer to keep close to the Putney shore. It may also be that, in both these cases, the 'nearest to the starboard side which is safe and practicable' will also be as close as possible into the port bank. In any event (as has happened in my experience between Beverley Brook and Barn Elms), if such coincides with the 'narrow channel or fairway', and when crossing, Rule 9 gives absolute priority to boats which can safely navigate only within it, so there is no conflict.

As for going with the tide, it is certainly more practicable to follow the line of greatest tidal flow. Assuming this to correspond usually with the deepest water, this does not conflict with the colregs so long as the boat does not 'cut corners', left-hand ones at any rate. She must be prepared to move to starboard (or indeed, anywhere else) so as not to impede the passage of a seagoing vessel coming the other way, and also in the event that such a vessel will wish to pass or overtake (Rule $9(b)$ ).

Thus, for all practical purposes, such a vessel can be regarded as having a moving exclusion zone around her, of a size to be determined by another vessel in danger of entering it. If such another vessel receives five or more short blasts on the whistle of such vessel (Rule 34(d)), she can be sure she has done so!

If Rowing Club rules state that the stroke is in charge of the boat, this would appear to be effective in making him the Master for the purposes of Byelaw $3(2)$. He not having a 'power-driven vessel', Byelaw 8 does not require him to have a competent cox or steersman ('steersman'), but Byelaws i I, I4, 20 \& 30 make him vicariously liable for the failure of his steersman to comply with most of the Byelaws, and it is difficult to think how the stroke can avoid such liability otherwise. On the basis that ignorance of the law is no excuse, both are required to have as deep a knowledge of the colregs as are the 
officers of an oceangoing supertanker but, if they do so, they will be entitled to as much respect.

Coxes are regarded by most coaches and strokes as robots for relaying commands. They should, however, ignore all directions from stroke or coach to proceed unless the cox is satisfied that it is safe to do so. If this means easying during a set piece, then so be it. The same applies to not paddling light while overtaking. Just as a ship entering harbour may be required to engage a pilot, it is the person in charge of the vessel pro tem. who retains full responsibility: the pilot, coach or stroke can only advise.

If the steersman feels the least bit intimidated he should immediately make for the nearest available landing point, and leave the crew to bring the boat back overland : there is not the slightest scope for compromise on safety. A useful comparison can be drawn with the Titanic, where the owners wanted a fast passage in spite of ice warnings: the Master appears to have allowed himself to be compromised.

Rule 5 states: 'Every vessel shall at all times maintain a proper look-out by sight and hearing... so as to make full appraisal of the situation and of the risk of collision.' For those 'navigating' vehicles on land, the Highway Code states that a driver must be 'able to stop within the distance he can see to be clear'. How many coxes can see only the navel of the stroke in front of them?

On land, a vehicle is required to carry an 'audible warning of approach'. Rule 33 (a) strictly regulates such equipment to be carried by vessels over 12 metres in length. They are hardly appropriate for rowing boats, but these are not specifically exempted. However, smaller boats can get away with being 'provided with some other means of making an efficient sound signal' (Rule 33(b)), and the steersman's voice would hopefully come within this definition!

This is no mere quibble, however, as Rule 34 (d) requires that, if a vessel is 'in doubt whether sufficient action is being taken by (an)other to avoid collision, the vessel in doubt shall immediately indicate such doubt by giving 5 or more short and rapid blasts on the whistle' (or, presumably, a hail). The reluctance of steersmen of boats about to be rammed by faster boats (who should know better) not keeping any sort of lookout to hail them is apparently due to their not having been introduced!

From long experience, it appears that most scullers and bow-steersmen are simply incapable of turning round to look where they are going. At least many never do, seeming to rely on other boats hailing them or, more likely, expecting them to get out of the way! Another boat having to hail should be regarded as a gross failure of watermanship, akin in flying terms to a near miss, and generally warranting a profound apology (but hardly ever receiving even a polite 'thank you' which, like mercy, is twice blessed).

Rule 6 states: 'Every vessel shall at all times proceed at a safe speed so that she can take proper and effective action to avoid collision and be stopped within an (appropriate) distance.' The steersman must have control of the boat. This means that he can stop the boat in an emergency. As a guide, however fast a boat can go, the steersman should be capable of stopping her dead in the water in her own length. Until he can do so, no other coaching should be given.

Rule 7 states: 'Every vessel shall use all available means... to determine if a risk of collision exists. If there is any doubt, such risk shall be deemed to exist.' It cannot be over-emphasized that, if there is a collision between rowing boats, prima facie both steersmen are jointly to blame; that is, each may be held responsible for all the damage suffered as a result of the collision (this has nothing to do with the 'knock for knock' arrangements entered into by insurers).

If a steersman wishes to displace that joint liability, he must show how the collision 
could have occurred if he had taken 'proper and effective action' to avoid it. This is very difficult to do, unless in exceptional circumstances, such as at night where the oncoming boat's light had gone out or fallen off: how does one prove that when it's at the bottom of the river? Or if one can prove that the approaching sculler was stone deaf, and didn't hear the hail.

At the turn of the tide, when two boats approach each other there are three possible scenarios :

(i) one boat thinks it is going with the tide, and the other thinks it is going against. Even if both are wrong, only one boat will be close to the bank;

(ii) both think they are going with the tide. The normal rule applies and both boats move to starboard to pass each other port-to-port: it should be noted that the equivalent Rule I4(a) applies only to power-driven vessels;

(iii) both think they are going against the tide, and will thus be close to the bank. While there is still no risk of collision so long as at least one vessel is keeping an effective lookout, to avoid this situation boats originally going with the tide should not move to the bank until they are sure the tide has turned.

Steersmen new to the Tideway should be particularly alert to the fact that rowing boats go faster than the tide and, while the tide may have turned at the boathouse, they are likely to overtake it quite a short distance away. The tide also turns at slightly different times at the centre of the river and the bank.

Going against the tide, a steersman should keep as close to the shore as is safe. He must allow all boats to overtake on the outside. As soon as another boat commences an overtaking manoeuvre, the steersman of the boat being overtaken must ensure that she can do so, even if this means paddling light or easying. The worst possible mistake is to move off when a boat is passing, but how often does it happen?! While multiple overtaking is not expressly prohibited, it is at the absolute risk of the outside boat.

It is very dangerous for boats to try to force their way through on the inside, as lessexperienced steersmen may move out into the fairway. Whatever the provocation, they should not do so. It is no less dangerous for slower boats to invite faster ones through on the inside, both for the slower boats, and on future occasions when faster boats try to force their way through (see 'stand-on vessels', below).

Going with the tide, a steersman who is in collision with a boat going against it is jointly liable unless he can show that he took proper and effective action to avoid collision. Exactly the same applies to a boat going in the same direction. It is the overtaking boat which has to keep out of the way of the boat being overtaken, even if this means easying during a set piece (Rule I $_{3}(\mathrm{a})$ ).

It is generally stated that rowing boats going with the tide must overtake to port (i.e. leave the boat being overtaken to starboard), but there appears to be nothing in either the Byelaws, the colregs, or the common-law rules to require this. The boat being overtaken may be out of her best water (intentionally or otherwise), and the idea is incompatible with Rule 34(c), which implies an option to overtake on either side. It appears to have arisen by analogy with the upriver rule.

This is most important, because steersmen are often taught to move to starboard when being overtaken, in direct contravention of Rule 17, which requires the 'stand-on' vessel (i.e. the one being overtaken) to 'keep her course and speed'. Such a move is dangerous, as it may easily lead to a 'walking along the pavement' situation of both boats trying to avoid each other and ending up by doing exactly the opposite. Except in 'head' races when the river is closed and the normal rules don't apply, again on this occasion it is much safer to keep to the letter of the law, even if this requires a strong nerve! 
If moving out of the best water to overtake means the overtaking boat is no longer moving fast enough to do so then, once the overtaking boat has committed herself to overtaking on one side or the other, the boat being overtaken may in accordance with Rule 9(e)(i) be inclined to reduce speed to permit this. However, such an event is likely to be so rare as to be hardly worth consideration, but should always be accompanied by 'sounding the appropriate signals' (Rule 34(c)(ii)). Thus the rule for being overtaken is identical for both up and down tide : keep one's course, and reduce speed if necessary.

Multiple overtaking is governed by Byelaw 15, sec. (d) of which states 'a vessel in a fairway above Tilburyness shall not overtake a vessel which is herself overtaking another vessel', which seems clear enough on the face of it, save that if vessel $A$ is overtaking vessel $B$ when both come upon vessel $C$, then presumably vessel A must stop overtaking vessel $B$ until both have overtaken vessel $C$. This is complicated by sec. (c), which states that 'a power-driven vessel shall not proceed abreast of another power-driven vessel except for the purposes of overtaking that other vessel'. Thus it appears perfectly permissible for oared (or sailing) boats to proceed as many abreast as they want, so long as they don't try to pass each other!

In the usual situation, where a sculler, say, is faced with 4 eights abreast bearing down on him, all thinking they're the fastest thing since Concorde and everybody else should go up the bank, if not already easied almost invariably the only safe course is to easy in accordance with Rule $8(\mathrm{e})$ 'to allow more time to assess the situation' well before an overtaking situation exists, and make sure they can hear him even if they're too careless to see him. It is very dangerous for a novice or other sculler to make a bolt for the far shore, as he is likely to find himself in the water with an eight on top of him.

2. OAR \& SAIL. The general principle would seem to be that, on the basis of relative manoeuvrability, oar gives way to sail (information kindly supplied by R. G. Crouch, Esq., H.M. Bargemaster and Clerk to the Company of Watermen \& Lightermen). However, 'give way to' is not the same as 'get out of the way of', so if in doubt the oared boat will usually easy (if not indeed already easied, as she is perfectly entitled to be) to let the sailing boat cross or otherwise pass.

Save for Rule 25 (d) (ii) relating to lights, no express reference is made by the colREgs to oared boats, whether seagoing or otherwise (and the Greek Trireme comes to mind). Rule 9(b) and Byelaw I 9 require sailing vessels not to impede the passage of vessels (presumably even oared ones) which can safely navigate only within a narrow channel or fairway, or any vessel over 20 metres long. Likewise, the same require an oared boat not to impede the passage of even a sailing boat in the same circumstances.

Rule i 8 (b) does not require sailing vessels to keep out of the way of oared vessels : nor does it do the opposite. While it may be that 'not impede the passage of' (Rule 9) is not identical to 'keep out of the way of' (Rule 18 ), it appears that no special rules are applied by the COLREGs between sailing and rowing boats; save only that, by what appears to be an oversight and by virtue of the fact that an oar (or for that matter, a paddle) is clearly within the definition of a machine (being a device where work is put in at one point and taken out at another), Rule 3 (b) arguably makes rowing boats 'power-driven vessels'! If this be so, then Rule 18 (a) gives express priority to sailing vessels.

While a sailing boat is arguably a machine, it is not 'driven by machinery', the essence of which is some moving part (of which an oar (lever) is the simplest form). By the same argument, while a jet engine may contain moving parts (the compressor), these are purely internal : thus a jet (or rocket) powered hydrofoil for instance is apparently not considered by the colRegs to be a 'power-driven vessel'!

3. NIGHTROWING. It is generally stated that oared boats should have a white light 
fore and aft, but the only actual provision appears to be Rule 25 (d), ss. (ii) of which requires such a vessel (even the Trireme in the open sea!) merely to 'have ready at hand an electric torch... showing a white light which shall be exhibited in sufficient time to avoid collision'. This gives no consideration at all to two or more oared vessels approaching each other and, in the crowded conditions of the Tideway, the conventional method is the only practical way of achieving this.

There was a time when boats were going up and down the river at night with the forelight pointing backwards, in the apparent hope that some of the light might occasionally catch the shirt of the bowman, and enough of that would reflect forwards to be visible to an approaching boat: it is, for about 5 yards! Though not expressly forbidden, flashing lights are becoming more common but (though effective) are a danger to navigation, as they represent a north cardinal buoy: the result could be similar to that achieved by the wreckers of old!

Two eights represent nearly 2 tonnes approaching each other at over 20 knots and, particularly at the turn of the tide, a steersman needs to be able to assess any situation at a glance. In the present 'push-me-pull-you' situation, he can't tell even if the boats in front are coming or going. In the interests of their own safety oarsmen are strongly urged to take advantage of the permission contained in the same subsection to display the same lights as sailing vessels; that is, red/green sectors forward.

If there is a single need for a change in the Byelaws, it is to make such lights compulsory.

\section{KEY WORDS}

I. Collision avoidance. 2. Rowing boats. 3. River navigation.

\section{Vertical Sextants give Good Sights}

\section{Mark Dixon}

Many texts stress the need for marine sextants to be held precisely vertical at the instant that the altitude of a heavenly body is measured. Several authors lay particular emphasis on the technique of 'rocking' the instrument in a small arc about the horizontal axis to obtain a good sight. Nobody, to the author's knowledge, however, has attempted to quantify the errors involved, so as to compare them with other errors inherent in determining celestial position lines. This paper sets out to address these issues and to pose the question: what level of accuracy of vertical alignment can reasonably be expected during marine sextant work at sea?

I. ROCKING THE SEXTANT. When a heavenly body is brought to tangency with the visible horizon it is particularly important to ensure that the sextant is held in a truly vertical position. To this end the instrument is rocked gently about the horizontal so that the image of the body describes a small arc in the observer's field of vision. As Bruce Bauer points out, ${ }^{1}$ tangency with the horizon must be achieved during the process of rocking and not a second or so after rocking has been discontinued. The altitude is recorded for the instant that the body kisses the visible horizon at the lowest point of the rocking arc, as in Fig. 2. The only other visual clue as to whether the sextant is vertical is provided by the right angle made by the vertical edge of the horizon glass mirror with the horizon. There may also be some input from the observer's sense of balance and his hand orientation.

2. ERRORS OFF THE VERTICAL. From a simple diagram in a vertical plane, Fig. I, it can be seen that, if an altitude is recorded with the sextant off the vertical, a slant 